\title{
475736 - COMPARISON BETWEEN ULTRASOUND-GUIDED SUPRACLAVICULAR, INFRACLAVICULAR AND AXILLARY BLOCKS
}

\author{
Gianluca Russo, Medical Doctor, De QH Tran, MD FRPC, Loreto Munoz, MD, \\ Roderick Finlayson, MD FRPC \\ Anesthesia, Montreal General Hospital, Montreal, QC, Canada
}

Introduction: Adjunctive ultrasonography for peripheral nerve blocks is the fastest growing area of regional anesthesia.1,2 Increasingly, anesthesiologists are describing new blocks or rediscovering old ones using echoguidance. This newly found enthusiasm, while commendable, can be a double-edge sword: if left unchecked, it will stray from evidence and science. Thus, in this single blind, randomized trial, we set out to formally compare three commonly used methods for brachial plexus anesthesia: ultrasound-guided supraclavicular (SCB), infraclavicular (ICB) and axillary (AXB) blocks

Methods: With the approval of our institutional Ethics Board, ninety patients undergoing upper extremity surgery distal to the middle third of the humerus will be randomly allocated to receive an ultrasound-guided SCB, ICB or AXB. A total of $35 \mathrm{ml}$ of lidocaine $1.5 \%$ with epinephrine $5 \mu \mathrm{g} / \mathrm{ml}$ will be used in each group. The primary outcome will be the performance time (defined as the sum of the imaging and needling times). The success rate (rate of surgical anesthesia), number of needle passes, procedural discomfort, onset of sensory blockade for the four main nerves of the brachial plexus (muscolocutaneus, median, radial and ulnar nerves) and total anesthesia-related time (sum of performance and sensory onset times) will also be assessed by a blinded observer. Side effects will be recorded as well.

Results: Forty seven patients have been recruited so far (Table 1). No difference in the rate of surgical anesthesia (94-100\%) was found. SCB and ICB were associated with similar performance times (301.61-320.54 sec), sensory onset times (22.5-23.08 $\mathrm{min})$, total anesthesia-related times (28.42-27.21 min) and number of needle passes (2.00). Compared to SCB and ICB, AXB required a longer performance time (515 vs 301.61320.54 sec; $\mathrm{p}<0.005)$. However, no differences in onset and anesthesia-related times were found. Procedural discomfort was low and similar in all three groups. SCB was associated with a higher incidence of side effects.

Discussion: Ultrasound-guided SCB, ICB and AXB constitute reliable methods for brachial plexus anesthesia. AXB requires a longer performance time than SCB and ICB; however sensory onset and anesthesia-related time are similar. SCB may be associated with a higher incidence of side effects.

References: 1. Can J Anaesth. 2007;54(8):662-74. 2. Reg Anesth Pain Med. 2007;32(5):434-9 


\begin{tabular}{|c|c|c|c|}
\hline & SCB & ICB & AXB \\
\hline $\mathrm{n}$ & 13 & 18 & 16 \\
\hline Performance Time (sec) & $320.54(+/-158.69)^{*}$ & $301.61(+/-181.18)^{* * *}$ & $514.87(+/-190.35)$ \\
\hline Sensory Onset Time & $23.08(+/-8.05)$ & $22.50(+/-6.58)$ & $18.57(+/-5.34)$ \\
\hline $\begin{array}{c}\text { Total Anesthesia-related } \\
\text { time(sec.) }\end{array}$ & $1705.15(+/-528.562)$ & $1635.88(+/-496.66)$ & $1635.56(+/-433.10)$ \\
\hline Surgical Anesthesia & 100 & 94.44 & 93.75 \\
\hline Number of Passes & $2.00(+/-1.24)$ & $2.00(+/-1.58)$ & $5.10(+/-1.76)$ \\
\hline Discomfort(scale 0-10) & $2.23(+/-1.87)$ & $3.11(+/-2.93)$ & $1.88(+/-1.15)$ \\
\hline Side Effects $(\%)$ & 50 & 16.66 & 12.50 \\
\hline Paresthesia (n) & 3 & 3 & 1 \\
\hline Vascular Puncture & 0 & 0 & 2 \\
\hline Horner'Syndrome & 4 & 0 & 0 \\
\hline
\end{tabular}

All data are expressed as mean $+/$ - standard deviation when appropiate * $\mathrm{p}=0.005$ compared to AXB (Student T test) ** $\mathrm{p}=0.002$ compared to AXB (Student T test) 